\title{
TRANSVERSALIZAÇÃO DA PERSPECTIVA DE GÊNERO OU INSTRUMENTALIZAÇÃO DAS MULHERES?
}

\author{
Marie France Labrecque \\ Université Laval
}

\begin{abstract}
Resumo: Este artigo é baseado numa pesquisa desenvolvida no sul do México' na qual tratouse de observar de que maneira uma recomendação formulada no plano internacional, como a transversalização do gênero, transforma-se em contextos nacional e local. Foi, de fato, a perspectiva de transversalização do gênero que norteou de maneira evidente a instauração do programa mexicano de igualdade de gênero e, por consequente, a criação dos institutos de igualdade de gênero. Sabe-se que esta abordagem vem se impondo desde a Declaração e o conjunto de ações da Conferência de Beijing, em 1995, quando foi declarado que, a partir de então, seria preciso levar em conta as consequências de toda decisão no âmbito do desenvolvimento dos homens e das mulheres respectivamente.
\end{abstract}

Palavras-chove: gênero; transversalização; Consenso de Washington; México; microcrédito.

\section{Transversalização do gênero e contexto de surgimento desta perspectiva}

A transversalização do gênero apresenta várias dimensões e é importante identificar qual dimensão abordarei. Para Sylvia Walby, ${ }^{2}$ por exemplo, a transversalização do gênero é, ao mesmo tempo, um conjunto teórico e um conjunto de práticas. Enquanto conjunto teórico, a transversalização do gênero consiste em revisar os conceitos-chave que possibilitam um entendimento mais adequado de um mundo enquanto elemento estruturado em função do gênero, em vez de propor uma teoria separada do gênero. Enquanto conjunto de práticas, a transversalizção do gênero constitui uma nova estratégia para o desenvolvimento como processo estruturado em função do gênero. ${ }^{3}$ É na qualidade de conjunto de práticas, no âmbito das políticas públicas de igualdade de gênero, que tratei o assunto da transversalização do gênero na minha pesquisa e é desta dimensão que falarei aqui.

Copyright ( 2010 by Revista Estudos Feministas.

"Esta pesquisa, intitulada "A construção social da mulher camponesa indígena no México: o caso do Yucatán", foi financiada de 2004 a 2007 pelo Conselho de Pesquisa em Ciências Humanas do Canadá (CRSH).

2 WALBY, 2003, p. 2.

${ }^{3}$ WALBY, 2003, p. 2. 
Minha pesquisa localizou-se numa perspectiva similar àquela de Bruno Lautier que considera que a globalização atual caracteriza-se pela aceleração dos quatro tipos de circulações previamente existentes: a circulação de pessoas, a circulação do dinheiro, a circulação das mercadorias e, por fim, a circulação das ideias, dos símbolos e das normas. ${ }^{4}$ Para mim, as recomendações em termos de igualdade de gênero são frutos da circulação das ideias, dos símbolos e das normas. Ao mesmo tempo que elas circulam, as recomendações, em termos de igualdade de gêneros, carregam todo um conjunto de outras ideias que vêm afetá-las e que, pensando bem, as desviam de seu objetivo original. A forma dominante que as recomendações tomaram em termos de igualdade de gênero é aquela da transversalização do gênero (o mainstreaming) que pode ser definida da seguinte forma: "[...] a (re)organização, a melhoria, o desenvolvimento e a avaliação dos processos políticos, de modo que uma perspectiva de igualdade de gênero seja incorporada a todas as políticas em todos os níveis e em todas as etapas, por todos os que têm poder de decisão". Essa definição origina-se do Conselho Europeu e é a mais frequentemente citada. ${ }^{5}$ Além disso, para o Conselho Europeu:

A igualdade de gênero significa uma visibilidade igual, o empowerment e a participação de ambos os sexos em todas as esferas da vida privada e da vida pública [...] A igualdade de gênero não é sinônimo de semelhança; ela não consiste em considerar os homens, seu estilo de vida e suas condições como a norma [...] A igualdade de gênero significa aceitar e valorizar também as diferenças entre as mulheres e os homens e os diferentes papéis que eles desempenham na sociedade.

Além disso, o Conselho Europeu insiste que é necessário que as mulheres e os homens participem de maneira igual na vida pública e que cada um conquiste a independência econômica. O meio de atingir essa participação e essa independência seria a educação como atesta justamente o terceiro objetivo do milênio para o desenvolvimento. ${ }^{7}$ Ainda segundo Walby, ${ }^{8}$ isso coloca a participação igual na vida política e pública, na educação e na conquista pela independência econômica como objetivo universal, enquanto outras esferas (notadamente a família e a tarefa de cuidar) permanecem sendo lugares da diferença.

Como meu objetivo aqui é fazer a ponte entre as transversalização do gênero e a instrumentalização das mulheres, faz-se necessário passar pelo contexto no qual a transversalização do gênero surgiu. Como Walby mais uma vez afirma:

A transversalização do gênero levanta questões importantes a respeito da relação entre os níveis global, transnacional e nacional da elaboração das políticas. A transversalização do gênero é uma iniciativa global mas ela não se desenvolveu globalmente de maneira igual ${ }^{9}$

${ }^{4}$ LAUTIER, 2006.

${ }^{5}$ Conselho Europeu (1998) apud WALBY, 2003, p. 7. Ver também o número 44 da revista Cahiers du Genre, 2008, cujo tema é: Gender Mainstreaming. De l'égalité des sexes à la diversité?

${ }^{6}$ Conselho Europeu (1998) apud WALBY, 2003, p. 7.

7 O terceiro objetivo é "Promover a igualdade dos sexos e a autonomização das mulheres". Seu alvo é "Eliminar as disparidades entre os sexos nos ensinos primários e médios até 2005 , se possível, e em todos os níveis do ensino até 2015, no máximo". Um dos três indicadores é o "Índice bruto de escolarização das meninas em relação ao dos meninos no ensino primário". Disponível em: <http://www.un.org/french/ millenniumgoals/gender.shtml>. Acesso em: 16 out. 2008.

${ }^{8}$ WALBY, 2003 , p. 8.

'Sobre a questão de saber se a transversalização do gênero faz parte das ideias e dos movimentos sociais que emergem antes no Ocidente, particularmente nos Estados Unidos, para serem em seguida transferidos para o resto do mundo, Walby ressalta, ao contrário, que não foi um simples processo de difusão dos países do centro para a periferia. Ela observa que a transversalização do gênero é associada a um conjunto de processos tais como: defesas de grupos da sociedade civil e movimento dentro de um mesmo país; redes de defesa transnacionais; comunidades epistêmicas e redes de especialistas etc. (WALBY, 2003, p. 19). 
[...] A aplicação da transversalização do gênero é irregular mesmo quando ela é liderada por uma entidade política transnacional.

Para mim, como também para várias outras autoras, o contexto de surgimento da transversalização do gênero é aquele do Consenso de Washington que corresponde a uma série de programas inspirados nas abordagens de Milton Friedman e dos Chicago Boys, com o objetivo de fazer com que o Estado deixe pleno espaço ao mercado. O Consenso de Washington concretizou-se nos programas de ajuste estrutural que foram emitidos no começo dos anos 1980, enquanto a crise da dívida internacional estava no auge. Os dois atores principais do Consenso foram o Banco Mundial e o Fundo Monetário Internacional (FMI). Enquanto o FMI almejava o resgate do equilíbrio financeiro, ao Banco atribuía-se a missão de converter os países em desenvolvimento à doutrina do liberalismo econômico, que acompanharia a diminuição do Estado e a conversão geral à competição econômica global. ${ }^{11} \mathrm{E}$ o que acontecia com as mulheres nesse contexto?

A história havia começado bem para as mulheres, já que o Banco Mundial, de alguma forma, as tinha 'descoberto', nos meados dos anos 1970, em decorrência da Confêrencia Internacional da Mulher na Cidade do México, em 1975, organizada pelas Nações Unidas. ${ }^{12}$ Em seguida, a declaração da Década Internacional das Mulheres 1975-1985 - contribuiria para tornar as mulheres mais visíveis, principalmente na área do desenvolvimento, o que se manifestou na prática na formulação de políticas, programas e projetos para as mulheres por diferentes entidades e, particularmente, pelas agências internacionais de desenvolvimento.

Os programas de ajuste estrutural vieram impor regimes de redução drástica aos países endividados da África, da América Latina e da Ásia. Os Estados pararam de contratar funcionários, o desemprego aumentou e os recursos, assim poupados, foram todos direcionados para o pagamento da dívida, à custa dos serviços sociais e dos setores da saúde. Segundo Sophie Bessis, é nesse momento que as mulheres se tornaram visíveis novamente. Ela escreve:

Em todas as frentes [...] por toda parte, as mulheres inventavam estratégias de sobrevivência para sair da crise. Elas recosturaram o tecido social que tinha sido rasgado por medidas econômicas e compensaram pela perda de status do cônjuge masculino (sendo que os homens foram os primeiros a pagar pela desaceleração do setor formal) [...] Durante os anos difíceis do ajuste estrutural no Sul, as mulheres mostraram ao Banco Mundial que tinham um papel econômico particularmente dinâmico e que eram as principais agentes na luta contra a pobreza, uma luta que o banco - pelo menos oficialmente - tinha como prioridade [...] Esses fatores converteram o Banco Mundial a uma espécie de feminismo que poderíamos chamar de pragmático.

Essa conversão do Banco Mundial não se deu somente a partir desses fatores. É preciso levar em conta o movimento a favor dos direitos humanos e os novos questionamentos a respeito do desenvolvimento em geral. Além da atenção que reaparece em relação à condição das mulheres, esses movimentos e questionamentos favoreceram o ressurgimento de novas abordagens, tais como a do desenvolvimento de base (bottom-up) e também um novo interesse para com os autóctones.

${ }^{10}$ WALBY, 2003, p. 18.

$"$ Sophie BESSIS, 2003, p. 640

${ }^{12}$ É preciso observar, no entanto, que esta 'iniciativa' das Nações Unidas foi consequência de reivindicações feministas a este respeito.

${ }^{13}$ BESSIS, 2003, p. 640 
Fala-se agora de uma era pós-Consenso de Washington, na medida em que o 'social' é reintroduzido nas recomendações de desenvolvimento econômico. Consideramos que, de fato, o Consenso de Washington mostrou-se ineficiente com a crise na Argentina em 2002. ${ }^{14}$ A fé dos 'fundamentalistas do mercado', inerente ao Consenso, teria sido abalada por esta e outras crises que lhe sucederam no mundo na ocasião da virada do milênio. ${ }^{15} \mathrm{O}$ novo consenso recomenda que as instituições devam, doravante, fomentar e incentivar o crescimento econômico. Admite-se, finalmente, que os mercados são inevitavelmente imbricados em estruturas sociais maiores. De agora em diante, é a teoria do capital social que prevalece, mas também a lógica da segmentação, a abordagem dos direitos de propriedade, a governança. ${ }^{16}$ Segundo Suzanne Bergeron, "o que é novo em relação à teoria do capital social, no contexto do desenvolvimento internacional, é que a cultura e as instituições são vistas como uma solução dos problemas de subdesenvolvimento e da pobreza". ${ }^{17}$ Nesse novo Consenso de Washington, a temática do gênero representa uma peça central. ${ }^{18}$ Apesar de a maioria dos autores consultados atribuírem a perspectiva da transversalização do gênero à Conferência de Beijing, em 1995, outros concordam em afirmar que foi, acima de tudo, a partir de 2001 que a integração do gênero ao conjunto da estratégia do Banco Mundial se tornou sistemática. Coloca-se a ênfase, a partir desse momento, na relação entre desigualdade de gênero e pobreza. ${ }^{19}$ À primeira vista, poderíamos pensar que essa ênfase é promissora. No entanto, é preciso relembrar aqui o que vários autores chamam de fundamentalismo do mercado, ao qual fiz alusão anteriormente. O fundamentalismo do mercado é definido da seguinte maneira: "[...] [uma] construção socioeconômica da sociedade acompanhada de uma visão de mundo que reforça este sistema". ${ }^{20}$ O neoliberalismo está no centro dessa construção, já que ele significa a supremacia do mercado sobre a vida das pessoas. ${ }^{21}$

Segundo Sophie Bessis:

O fato de que as mulheres, mesmo nas condições as mais difíceis, são capazes de captar o dinamismo da esfera comercial representa, para os especialistas do Banco Mundial, uma etapa significativa em direção à generalização tão almejada das forças do mercado. A questão dos direitos das mulheres é secundária para uma instituição que vê as mulheres antes de tudo como um novo tipo de ator econômico, uma possível garantia de estabilidade social em tempos em que é cada vez mais difícil atingir a estabilidade. O Banco Mundial instrumentalizou, desse modo, as mulheres para que sua promoção não seja um fim em si, mas sim um meio de operar as políticas do Banco para o crescimento econômico e a erradicação da pobreza.

Porém, trata-se realmente de instrumentalização das mulheres?

\section{Instrumentalização das mulheres}

Tal como é definida notadamente por Alexandra Dobrowolsky, ${ }^{23}$ a instrumentalização das mulheres ocorre quando estas são colocadas de maneiras altamente estratégicas. De

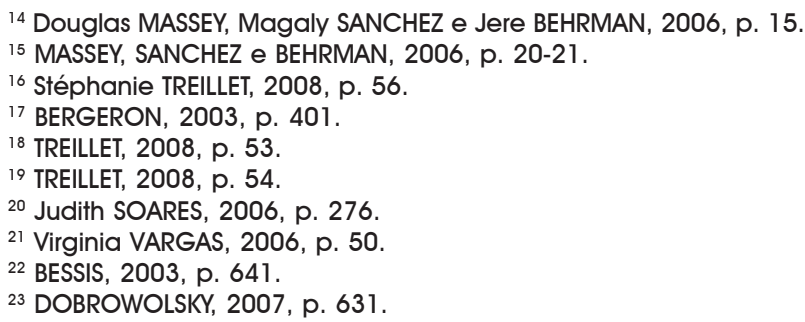


acordo com essa autora, a instrumentalização das mulheres, tanto quanto a racialização ou a invisibilização das mulheres, são envolvidas nos processos de mercantilização, estes concomitantes à corrida para a segurança nos dias atuais. Ela ainda afirma que a mercantilização agrava as desigualdades econômicas e contribui para a invisibilização e instrumentalização das mulheres. ${ }^{24}$ Além disso:

[...] a mercantilização significa também que várias das responsabilidades do Estado recaem seja sobre o mercado ou seja sobre a família, presumindo que as mulheres vão assumir o lugar na área da saúde. O trabalho subvalorizado e gratuito das mulheres, em casa, pode então ter efeitos negativos nas oportunidades de trabalho remunerado. É nesse sentido que as mulheres são usadas de maneiras muito instrumentais, o que reforça as desigualdades de gênero.

Em outras palavras, a lógica instrumental consiste em considerar as mulheres como um recurso, como um investimento lucrativo. ${ }^{26}$ No aspecto do desenvolvimento internacional, a instrumentalização do gênero refere-se à forma sob a qual as recomendações internacionais chegam às organizações do desenvolvimento, seja sob a forma de um conjunto de fórmulas e maneiras de agir (package) que favorecem uma aplicação mais mecânica das medidas visando à igualdade de gênero, ou retomando uma dicotomia que está no centro da instrumentalização - a satisfação das necessidades práticas de gênero prevalece sobre a dos interesses estratégicos de gênero. ${ }^{27}$

É importante lembrar que estamos numa época de flexibilização do mercado, o que significa mais trabalho precário, um trabalho que cabe, frequentemente, às mulheres, ou ainda mais trabalho feminizado, ou seja, subpago; e que, em contrapartida, essa situação contribui para uma maior insegurança econômica. Nesse contexto, podemos nos juntar a Treillet para afirmar que:

[...] o papel do Estado fica subordinado à lógica do mercado enquanto princípio de distribuição dos recursos e dos fatores de produção [...] mais geralmente os agentes econômicos devem ser colocados em condições de poder explorar um campo maior de oportunidades. O aumento da atividade das mulheres [...] [é] um fator essencial, tanto para melhorar a renda das famílias e sua distribuição intrafamiliar a curto prazo, quanto para aumentar o investimento (sanitário, educacional) realizado em crianças menos numerosas, a médio prazo.

Essa autora acrescenta: "O incentivo ao microcrédito pelo Banco Mundial segue uma lógica de estímulo a um crescimento econômico que inclui os mais pobres". ${ }^{29}$ Foi justamente o que eu encontrei no México, ou seja, as recomendações de transversalização de gênero se concretizavam, pelo menos no Ministério do Desenvolvimento Rural, através da adesão ao acesso ao microcrédito para as mulheres do meio rural. Poderíamos, talvez, indagar se essa adesão provém de uma compreensão equivocada da teoria que subentende a perspectiva de transversalização do gênero. No entanto, como mencionei no início deste artigo, a transversalização do gênero consiste num conjunto de teorias, porém também de práticas. Pode acontecer que as práticas se apoiem em suas próprias dinâmicas, suas próprias lógicas.

24 DOBROWOLSKY, 2007, p. 643

${ }^{25}$ DOBROWOLSKY, 2007, p. 644

${ }^{26}$ TREILLET, 2008, p. 64.

${ }^{27}$ Raman SOHAL, 2005, p. 670-672.

${ }^{28}$ TREILLET, 2008, p. 61.

${ }^{29}$ TREILLET, 2008, p. 62. 


\title{
Instrumentalização das mulheres e microcrédito no México
}

Durante uma das minhas pesquisas no México, entre 2004 e 2007, tentei acompanhar a transversalização do gênero no plano local, examinando um pequeno programa para as mulheres do meio rural, encabeçado pelo Ministério do Desenvolvimento Rural e da Pesca do Estado do Yucatán. O programa consistia em liberar empréstimos para a criação de pequenos projetos geradores de renda, seja na área da agricultura, da apicultura ou do artesanato. Como se tratava de um programa criado pelo Ministério, ele tinha que respeitar a recomendação de transversalização de gênero. Com efeito, um dos funcionários masculinos encarregados do programa havia testemunhado a transversalização de gênero no Estado de Yucatán. Eis como, durante a entrevista que realizei com ele em 2004, descreveu-me a situação:

\begin{abstract}
Na realidade, começamos a falar de igualdade e de gênero somente no ano 2000, na ocasião da eleição do Presidente Vicente Fox [do partido da ação nacional e que encerrava mais de 70 anos de domínio de um único partido, o partido da revolução institucional]. É a partir daí que as políticas de gênero começaram a mudar, que começamos a falar de igualdade. Para que as políticas federais cheguem ao nível local, é um processo enorme, uma mudança radical, ainda mais que o regime anterior tinha acostumado as mulheres a muito paternalismo, na realidade, tanto os homens quanto as mulheres. Quando o partido da ação nacional toma o poder, é daí que o nome do Instituto da Mulher muda para Instituto da Igualdade de Gênero. Em seguida, formaram-se oficinas nas quais algumas pessoas de cada ministério participaram. Como, por exemplo, para o Ministério do Desenvolvimento Rural, foi somente eu quem foi, apesar do ministério contar com centenas de pessoas. (fonte oral) ${ }^{30}$
\end{abstract}

Já nessa parte do depoimento desse funcionário, podemos localizar algumas indicações importantes a respeito da transversalização de gênero, isto é: 1) que o discurso sobre a igualdade de gênero é proferido por um novo regime que levanta uma bandeira mais democrática; 2) que não é porque aderimos a uma política internacional no nível federal que isso se aplicará facilmente no nível local; 3) que uma das primeiras manifestações da abordagem da transversalização do gênero foi feita num plano simbólico através da mudança de nome do Insituto da Mulher pelo Instituto de Igualdade de Gênero; e, por fim, 4) que a formação dos funcionários envolveu somente alguns deles, vindo de diferentes ministérios. Porém, deixemos isso de lado no momento a fim de prosseguir com o depoimento do funcionário.

Durante as oficinas, tive a impressão de que os funcionários do instituto, mesmo tratandose de pessoas bem instruídas, não sabiam realmente o que era gênero e nem igualdade. Inclusive a mudança de nome do Instituto foi proposta pela Diretora do Instituto e submetida ao voto dos participantes das oficinas enquanto não tínhamos a menor ideia do que se tratava [...] No final das contas, o que eu consegui entender é que a igualdade é a igualdade de oportunidades para todos, tanto para o homem quanto para a mulher. Quanto ao gênero, temos que começar a usá-lo tanto quando se trata do homem quanto da mulher em todas as políiticas de desenvolvimento das comunidades [...]. Mas o obstáculo principal não é esse. No regime anterior, infelizmente, muitos funcionários não tinham nenhuma consideração pelas populações do meio rural. Eles só queriam seus salários e implementavam seus projetos de qualquer jeito. Ou então eles se aproveitavam do fato de que as pessoas morriam de fome no campo para manipulá-

\footnotetext{
${ }^{30}$ Entrevista realizada, em 2004, com um funcionário do programa para as mulheres do meio rural, encabeçado pelo Ministério do Desenvolvimento Rural e da Pesca do Estado do Yucatán.
} 
las distribuindo ajudas pontuais para fins partidários. Mesmo com a mudança de regime, as pessoas esperam que o desenvolvimento aconteça desta maneira, ou seja, que lhes demos apoio em troca de seus votos. Daí, você pode imaginar a igualdade de gênero no meio de tudo isso [...]. Se você for ao vilarejo e perguntar o que é o gênero, o que é igualdade, não encontrará ninguém que possa responder. [...] Entretanto, na cidade, todo mundo joga com esse contexto. No Instituto da Mulher, afirma-se que as políticas chegaram agora ao campo "com um toque de igualdade e de gênero". (fonte oral)

Entre todos os elementos importantes levantados por esse funcionário, ressalto dessa vez: 1) o caráter autoritário com o qual ocorreu a mudança de nome do Instituto da Mulher para o Instituto da lgualdade de Gênero - ninguém sabia do que se tratava, nem mesmo os funcionários do instituto; 2) meu interlocutor, bem ou mal, acabou conseguindo ter uma ideia do que é a igualdade de gênero, mesmo que de uma maneira redutora dentro de uma perspectiva que poderíamos atribuir a da semelhança; 3) não mudamos nossos velhos hábitos da noite para o dia, considerando que o paternalismo reinou durante mais de 70 anos no México; 4) o clientelismo partidário e o oportunismo político, ou seja, a ausência de democracia, constituem sérios obstáculos para a transversalização do gênero; e, por fim, 5) a fome constitui um fator principal que dificulta tanto a democracia quanto 0 desenvolvimento e a igualdade.

Mas em que consiste exatamente a prática? No México existe um Programa nacional de microcrédito e um Instituto Nacional do Banco Social que estimula as organizações civis e as ONGs a participarem na distribuição do crédito para os 'setores marginalizados'. ${ }^{32}$ Geralmente, o microcrédito envolve quantias entre 500 e 1.000 pesos, ou seja, 50 a 100 dólares, aproximadamente. É evidente que a difusão do acesso ao microcrédito no México se deu no trilho de recomendações internacionais. Como observa Ximena Bedregal, faz mais de uma década que essa abordagem foi adotada pelo FMl, pelo Banco Mundial, pelas agências de desenvolvimento e pelos governos dos países mais poderosos. Ela ainda nota que os discursos dominantes nesse assunto colocaram o microcrédito como meio de acesso à igualdade para as mulheres. ${ }^{33}$

Um dos problemas que aparecem, pelo menos no que eu pude observar no México, é a seleção das pessoas que podem receber o tão falado microcrédito. Não devemos esquecer que ter acesso ao microcrédito é sinônimo de endividar-se. As mulheres do campo são, particularmente, receosas ou contrárias à perspectiva de gerar qualquer dívida. Em tal contexto, não é de se surpreender que o primeiro contato para fazer o empréstimo às mulheres do campo parece ser feito graças à iniciativa dos funcionários do Ministério. Uma das artesãs entrevistadas lembra:

O técnico [o funcionário] veio e me disse: 'se você quiser, teria uma possibilidade da gente reconhecer seu produto, se você quiser vendê-lo e ter um pouco de capital, nós a convidamos, em nome da diretora do programa, a vir nas feiras [de exposição dos produtos artesanais], daí talvez você poderá conseguir um empréstimo. (fonte oral) ${ }^{34}$

Inclusive, o termo microcrédito já diz muito, e faz até sua propaganda com experiências de Mohammad Yunus no Bangladesh e do Grameen Bank. O que nunca é dito é que uma das razões básicas do sucesso do Grameen Bank foi que milhões de camponeses de pequeno e médio portes, como também trabalhadores industriais do Bangladesh, tinham

${ }^{31}$ Entrevista realizada, em 2004, com um funcionário do programa para as mulheres do meio rural, encabeçado pelo Ministério do Desenvolvimento Rural e da Pesca do Estado do Yucatán.

32 Ximena BEDREGAL, 2001.

33 BEDREGAL, 2001

${ }^{34}$ Entrevista com artesã, em 2005, do povoado de Halachó. 
sido arruinados anteriormente pelos programas de ajuste estrutural do FMI. No entanto, foram justamente os camponeses sem-terra e os desempregados que se tornaram os clientes do Grameen Bank. Além disso, hoje os microempréstimos sustentam 11.000 empregados na Grã-Bretanha... e a maioria são homens. ${ }^{35} \mathrm{E}$, mais ainda, enquanto esses grupos solidários encontram-se no centro da abordagem preconizada por Yunus, eu não vi nada parecido com isso no México. O crédito é atribuído individualmente. Segundo Linda Mayoux, ${ }^{36}$ há três paradigmas de microcrédito: o paradigma do empowerment das mulheres; aquele da redução da pobreza; e, por fim, aquele da estabilidade financeira baseada no desenvolvimento de um sistema bancário lucrativo voltado para as populações pobres. Os dois primeiros podem ser englobados no termo microcrédito global e o terceiro no termo microcrédito minimalista. Devo dizer que, apesar das pretensões do governo de ter um programa que visa ao empowerment das mulheres e à redução da pobreza, o que eu vi pode ser resumido à versão minimalista, especialmente porque o microcrédito era concedido às mulheres de modo individual e por outros motivos sobre os quais não tenho tempo de me ater aqui.

As opções oferecidas às mulheres rurais, escolhidas pelo Ministério do Desenvolvimento Rural para o microcrédito, variam em torno dos projetos de artesanato, incluindo um caráter autóctone tanto no que diz respeito aos materiais, produtos e técnicas utilizadas, quanto aos símbolos ali referidos. Ao mesmo tempo, notamos que os produtos são adaptados ao gostos atuais e que, cada vez mais, eles são orientados para o turismo nacional e internacional. Na realidade, não é segredo para ninguém que o mercado internacional seja o alvo. Assim, em vez de fabricar somente redes para fins domésticos, as artesãs fazem, com a mesma técnica, redes para se balançar; e algumas delas tiveram até a ideia de fabricar redes miniaturas para animais de estimação! (Com certeza, esses objetos não têm utilidade para elas.) As artesãs confeccionam, também, roupas de todo tipo (blusas, roupas de banho, saias, robes, lenços, entre muitas outras) que o Ministério apresenta nos desfiles de moda, em ocasião de feiras comerciais periódicas tanto no México quanto no exterior. Alguns produtos são mais procurados que outros, na medida em que estão mais sujeitos a uma boa aceitação no mercado local e até mesmo no internacional. Na ocasião da Muestra Artesanal y Gastronomica Rural (Exposição de artesanato e de gastronomia rural), a diretora do programa afirmava que os produtos possuiam, doravante, uma apresentação melhor, uma melhor embalagem, que as artesãs dispunham agora de cartões de visita e que os produtos tinham também código de barras. ${ }^{37}$ As artesãs aproveitavam também das datas internacionais decretadas pelas Nações Unidas, tal como o Dia Internacional das Mulheres, o Dia da Mulher Rural etc., para montar quiosques de exposição e venda.

Em tal contexto, podemos entender que o microcrédito ajusta-se muito bem ao desenvolvimento neoliberal. Além de fazer parte de uma abordagem que visa integrar as mulheres à modernidade e de se basear no conceito das desigualdades e da descriminação como inerentes à tradição, ${ }^{38}$ o microcrédito seria um instrumento de transformação das mulheres em 'atores econômicos eficientes', sem gerar grandes despesas para o governo. Nesse sentido, observamos que as mulheres trocam raramente de empréstimos pequenos para empréstimos mais significativos. Elas são também mantidas em certos setores, muitas vezes pouco lucrativos, o que não contribui de maneira alguma à aquisição de bens ou a

\footnotetext{
${ }^{35}$ BEDREGAL, 2001

${ }^{36}$ MAYOUX, 2006

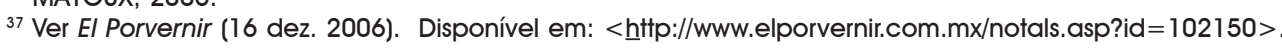
Acesso em: 16 dez. 2006

${ }^{38}$ BERGERON, 2003, p. 408.
} 
reforçar seu poder. ${ }^{39} \mathrm{Na}$ realidade, poderíamos similarmente a Treillet, ${ }^{40}$ perguntarmo-nos: 'poder sobre quê, sobre quem?'. O autor ainda diz: "Não se trata aqui de uma tomada coletiva de poder pelas populações oprimidas do terceiro mundo, mas de um reforço da possibilidade de sucesso individual de alguns, graças a um acesso facilitado ao mercado". ${ }^{41}$ Um exemplo de sucesso individual é o de Madame Peregrina Cutz Tec, ${ }^{42}$ que criou uma espécie de boneca vestida com as roupas típicas das mulheres nativas do Yucatán. A boneca era inicialmente destinada à sua filha, mas ela chamou a atenção de uma funcionária que lhe pediu outros exemplares para uma loja onde os turistas brigaram para conseguir comprar uma delas. Em alguns meses, a boneca, vendida por 120 pesos, ${ }^{43}$ foi parar não somente no mercado de Mérida, mas também na Califórnia e alguns exemplares foram mandados para a Alemanha, Nova York e Chicago, ${ }^{44}$ sem dúvida através de uma rede de imigrantes. No entanto, quando entrevistei Madame Cutz Tec, logo depois de o programa ter lhe concedido um crédito relativamente alto, ela estava na dúvida se aceitava por medo de dar errado e de se endividar. Por outro lado, ela tinha receio de ter que trabalhar sob pressão e, principalmente, de ter menos tempo para sua família. Mas, por fim, ela acabou sendo convencida.

Emma Zapata e Janet Townsend, que também desenvolveram suas pesquisas no México, ressaltam também que o microcrédito favorece um empreendimento individual. Elas afirmam que o microcrédito representa atualmente uma das ações mais importantes dentro da indústria do desenvolvimento sem, no entanto, trazer alguma solução para a pobreza. Com Ankie Hoogvelt, ${ }^{45}$ essas autoras consideram que essa estratégia de desenvolvimento faz parte de um sistema emergente de governo global. As agências e as ONGs que promovem essa estratégia representariam então a vanguarda do capitalismo, na medida em que suas equipes ensinam aos pobres e aos destituídos "como entrar no mundo da produção em troca de um lucro". ${ }^{46}$ Não se trata aqui de criticar de maneira unilateral a instrumentalização, pois, como escreve Sohal, podemos desse jeito chegar a uma verdadeira paralisia política. ${ }^{47}$ Por outro lado, se considerarmos que uma maior justiça social é desejável, as medidas de erradicação da pobreza devem ser pensadas no sentido de requestionar estruturas patriarcais maiores, o que a transversalização do gênero não parece realmente favorecer, pelo menos sua dimensão prática, devido a uma ausência de perspectiva crítica a respeito do neoliberalismo.

\section{Conclusão}

Em outras palavras, mesmo que as mulheres sejam mais participativas, pelo menos no contexto do programa que observei, mesmo que elas sejam mais integradas no mercado de trabalho ou ainda envolvidas na geração de renda, as desigualdades, particularmente entre os sexos, persistem. É o que Jules Falquet constata ao examinar as estratégias do

\footnotetext{
39 LAIRAP-FOUNDERSON, 2002. In: SOHAL, 2005, p. 668.

40 TREILLET, 2008, p. 63.

41 TREILLET, 2008, p. 63

${ }^{42} \mathrm{O}$ nome de Madame Cutz Tec circulou bastante na imprensa local, o que torna inútil a preservação de seu anonimato quanto se trata da famosa boneca.

${ }^{43}$ Talvez seja útil lembrar que o salário mínimo é de menos de 45 pesos por dia em Yucatán e que a maioria dos trabalhadores ganham menos de dois salários mínimos por dia.

${ }^{44}$ Esta notícia provém de um boletim do serviço de relações públicas do Ministério do Desenvolvimento Rural e da Pesca (SDRyP), de 22 de fevereiro de 2007.

45 HOOGVELT, 1997.

${ }^{46}$ ZAPATA e TOWNSEND, 2002, p. 71.

${ }^{47}$ SOHAL, 2005, p. 672.
} 
Estado internacional, especialmente aquelas da ONU, quanto ao "gênero e desenvolvimento", ${ }^{48}$ das quais se originam, sem dúvida, os programas de microcrédito para as mulheres no mundo inteiro. De fato, esses programas geram mudanças, porém sem melhorar a justiça social, os direitos humanos e a cidadania. Jules Falquet colocou a hipótese de que essa situação depende dos limites intrínsecos dos novos paradigmas e práticas, tais quais o empowerment, a transversalização da perspectiva de gênero e o microcrédito. Para essa autora, a maneira com a qual o termo 'empowerment' é usado é tão geral que a palavra perde seu sentido. Além disso, guardamos somente o aspecto individual do processo.

Mesmo quando na formação de um grupo permanece uma condição para a obtenção do microcrédito, as prioridades financeiras levam, frequentemente, a uma aplicação instrumental dos programas à custa dos processos mais longos e mais difíceis de conscientização e de empowerment; o resultado de tal medida é a produção e a conservação das hierarquias existentes de gênero. ${ }^{49} \mathrm{Em}$ sua análise das estratégias do Banco Mundial, baseado no capital social, Rankin encontrou que, na realidade, o objetivo central da microfinança é, acima de tudo, a saúde do sistema financeiro, pelo menos em certos contextos onde os programas de microcrédito são aplicados sem ter ligação com outras iniciativas comunitárias: é a abordagem "minimalista". Ela ressalta que: "Respondendo às prioridades de regulação do mercado no plano macroeconômico, a abordagem minimalista reduz a microfinança às dimensões estritamente financeiras de diminuição da pobreza (o crédito, a poupança e, cada vez mais, os seguros e outros instrumentos financeiros)". ${ }^{50}$ Porém, mais importante ainda, segundo Falquet, é que esse tipo de medida não traz nenhuma solução a longo prazo para o constante empobrecimento das mulheres. ${ }^{51} \mathrm{E}$ se tivermos ainda dúvidas sobre a articulação do microcrédito com o fundamentalismo do mercado, eis uma observação muito forte de Ximena Bedregal: "Não se empresta para comprar uma cabra para fornecer leite às crianças, mas somente para produzir objetos que podem ser vendidos no mercado e [...] compra-se o leite no mercado". ${ }^{52}$ Trata-se então de fazer o dinheiro circular que, de outro modo, não circularia ou ficaria fora dos circuitos bancários e financeiros.

Após mais de dez anos de práticas ligadas à transversalização do gênero, tal como o microcrédito, mas também a análise sexo-específica, da qual não falei aqui, observamos certos deslizes que se expressam por terem em conta a simetria assumida da condição dos homens e das mulheres e por uma negação implícita das relações de poder diferentes de acordo com o gênero tanto no nível local quanto estrutural. ${ }^{53}$ Nos países do norte, isso aparece claramente no crescimento da corrente masculinista. Nos países do sul, alvos das políticas internacionais do desenvolvimento, as estruturas patriarcais maiores não somente são esquecidas, mas também são esquecidas as relações de poder entre os homens e as mulheres, o que coloca estas últimas em posição de clara desvantagem no processo de desenvolvimento.

Nesse sentido, Eva Rathgeber afirma que mesmo a recente avaliação, feita em março de 2005, do progresso realizado desde uma década da ocasião da reunião Beijing + 10 "não conseguiu abordar a principal crítica feminista que afirma que as mulheres continuam oprimidas no seio de sistemas patriarcais" ${ }^{54}$ Ela acrescenta que a análise de

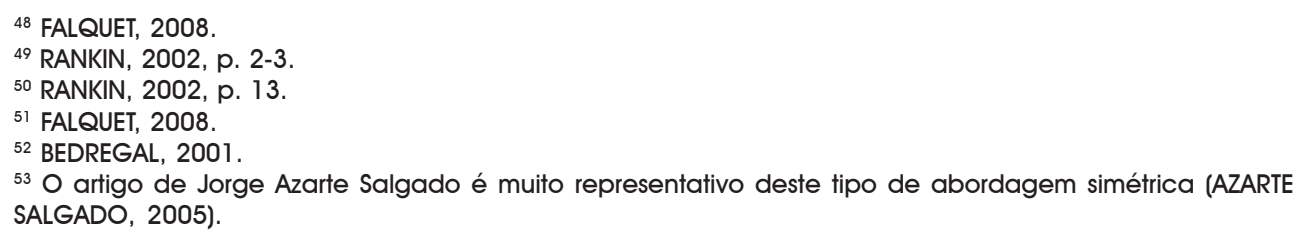


gênero tornou-se um fim em si e que não foi muito eficiente para mudar estruturas sociais existentes. ${ }^{55}$ Conclui, a partir disso, que as relações de poder permanecem intactas. ${ }^{56}$

Em suma, a transversalização do gênero é uma 'prática reguladora' da governança internacional provinda do sistema das Nações Unidas. ${ }^{57}$ Desse modo:

[...] na medida em que a transversalização de gênero introduz novas linhas de visibilidade que ligam as mulheres a novas áreas nas quais, na realidade, recursos podem ser alocados, certos efeitos de gênero (tão limitados quanto podem ser) podem ocorrer; as mulheres adquirem, em certo sentido, algumas "capacidades" de conduzir ações que, até então, não teriam sido possíveis. Vale a pena examinar, então, quais tipos de mulheres e quais tipos de políticas foram criadas pela transversalização de gênero, tal qual ela é difundida pelas organizações internacionais. ${ }^{58}$

Ou seja, a capacidade das mulheres aumenta - uma 'nova' mulher rural com novas possibilidades nasce - sem que seja questionado o panorama social e políico. ${ }^{59}$ As causas estruturais das desigualdades de gênero não são, assim, colocadas em dúvida; tampouco as relações de poder em todos os níveis.

\section{Referências bibliográficas}

ARZATE SALGADO, Jorge. "Elementos para construir una teoría de la equidad entre géneros. El caso de la política de lucha contra la pobreza extrema en México". In: BORDI, Ivonne Vizcarra (Dir.). Género y poder: diferentes experiencias, mismas preocupaciones. México: Universidad Autónoma del Estado de México, 2005. p. 205-222.

BEDREGAL, Ximena. "Microcréditos, política global para unir a las mujeres pobres al mercado mundial". Triple Jornada, n. 33 (Supplément mensuel du quotidien mexicain La Jornada), 2001.

BERGERON, Suzanne. "The Post-Washington Consensus and Economic Representations of Women in Development at theWorld Bank". International Feminist Journal of Politics, v. 5, n. 3, 2003. p. 397-419.

BESSIS, Sophie. "International Organizations and Gender: New Paradigms and Old Habits". Signs: Journal of Women in Culture and Society, v. 29, n. 2, 2003. p. 633-647.

CAHIERS DU GENRE. Gender Mainstreaming. De l'égalité des sexes à la diversité, v. 44, 2008.

DOBROWOLSKY, Alexandra. "(In)Security and Citizenship: Security, Im/migration and Shrinking Citizenship Regimes". Theoretical Inquiries in Law, v. 8, n. 2, 2007. p. 629-662.

FALQUET, Jules. De gré ou de force. Les femmes dans la mondialisation. Paris: La Dispute, 2008.

HOOGVELT, Ankie. Globalization and the Postcolonial World: The New Political Economy of Development. Baltimore: The Johns Hopkins University Press, 1997.

LAUTIER, Bruno. "Mondialisation, travail et genre: une dialectique qui s'épuise". Cahiers du Genre, n. 44, 2006. p. 39-64.

MASSEY, Douglas S.; SANCHEZ, Magaly R.; BEHRMAN, Jere R. "Of Myths and Markets". Annals, AAPSS, n. 606, 2006. p. 8-31.

MAYOUX, Linda. “Women's Empowerment Through Sustainable Microfinance: Rethinking Best

\footnotetext{
${ }^{54}$ RATHGEBER, 2005, p. 580.

55 RATHGEBER, 2005, p. 589

${ }^{56}$ RATHGEBER, 2005, p. 589-590

57 Lynne PHILLIPS, 2005, p. 653.

${ }^{58}$ PHILLIPS, 2005, p. 659.

${ }^{59}$ PHILLIPS, 2005, p. 659.
} 
Practice". In: Overview Paper Prepared for Gender and Finance Website. Disponível em: $<$ http://www. genfinance.info>. Acesso em: 9 nov. 2009.

PHILLIPS, Lynne. "Gender Mainstreaming: The Global Governance of Women?". Canadian Journal of Development Studies, v. XXVI, Special Issue, 2005. p. 651-663.

RANKIN, Katharine N. "Social Capital, Microfinance, and the Politics of Development". Feminist Economics, v. 8, n. 1, 2002. p. 1-24.

RATHGEBER, Eva. "Gender and Development as a Fugitive Concept". Canadian Journal of Development Studies, v. XXVI, Special Issue, 2005. p. 579-591.

SOARES, Judith. "God and Caesar are One". Peace Review: A Journal of Social Justice, v. 18, n. 2, 2006. p. 275-280.

SOHAL, Raman. "Strategic Engagements: Exploring Instrumentalist Approaches to Engendering Development". Canadian Journal of Development Studies, v. XXVI, Special Issue, 2005. p. 665-676.

TREILLET, Stéphanie. "L'instrumentalisation du genre dans le nouveau consensus de Washington". Actuel Marx, v. 44, n. 2, 2008. p. 53-67.

VARGAS, Virginia. "Women's Rights, Economic Justice and Citizenship: What Role for the United Nations?". Development, v. 49, n. 1, 2006. p. 49-51.

WALBY, Sylvia. Gender Mainstreaming. Productive Tensions in Theory and Practice. Contribution to ESCR Gender Maintreaming Seminars. 2003. Disponível em: <http://www.leeds.ac.uk/ sociology/people/swdocs/Gender\%20Mainstreaming\%200verview.pdf > . Acesso em : 10 oct. 2008.

ZAPATA, Emma; TOWNSEND, Janet G. "Los agentes externos y el empoderamiento personal". In: ZAPATA, Emma et al. Las mujeres y el poder. Contra el patriarcado y la pobreza. México: Plaza y Valdez, 2002. p. 67-85.

[Recebido em julho de 2010 e aceito para publicação em outubro de 2010]

\section{Gender Mainstreaming or Instrumentalization of Women?}

Abstract: This question is discussed on the basis of first hand data collected in Mexico between 2004 and 2007. The research aimed at examining how gender equity policies elaborated at the international level using an approach known as "gender mainstreaming" are transformed within national and local contexts. In a first step, the context of the emergence of the gender mainstreaming approach is reconstituted, and in a second step we try to clarify how and under what circumstances, in a country like Mexico, women can be instrumentalized within this approach, as for example, when gender mainstreaming is applied without any critical vision as it is so under neoliberalism. The main example rests on the case of microcredit for maya women in the state of Yucatan.

Key words: Gender, Transversalization, Washington Consensus, Mexico, Microcredit 